\title{
Correction to: Loneliness and Quality of Life in Older Adults: The Mediating Role of Depression
}

\section{Batool Ahadi ${ }^{1} \cdot$ Bentolhoda Hassani $^{1}$}

Published online: 16 March 2021

(c) Springer Science+Business Media, LLC, part of Springer Nature 2021

\section{Correction to: Ageing International https://doi.org/10.1007/s12126-021-09408-y}

The original article has been corrected. Author affiliation "Department of Psychology, Faculty of Educational Sciences \& Psychology, Alzahra University, Tehran, Iran" should be "Department of Psychology, Faculty of Education and Psychology, Alzahra University, Tehran, Iran".

Publisher's Note Springer Nature remains neutral with regard to jurisdictional claims in published maps and institutional affiliations.

The original article can be found online at https://doi.org/10.1007/s12126-021-09408-y.

\section{Batool Ahadi}

b.ahadi@alzahra.ac.ir

1 Department of Psychology, Faculty of Education and Psychology, Alzahra University, Tehran, Iran 